\title{
'Now we got truck everywhere, we don't travel anywhere': A phenomenology of travelling by community mutika in the northern Kimberley, Western Australia
}

\author{
Anthony Redmond
}

Motor vehicles tend to be highly personalised in all kinds of cultural milieus. The process of personalisation is primarily achieved through a projection of the travelling subject's own bodily schema onto the body of the vehicle. These strongly libidinal/narcissistic bodily investments are made visible, for example, in the penchant for personalised numberplates that expand parts of a vehicle owner's/user's bodily ego into that of their vehicle, in how some male truck drivers paint their wife's or girlfriend's name on their cab panels so that the driver is imaginarily travelling inside the desired woman's cab/body, or even in the way we might speak of a vehicle being 'gutsy' or 'gutless'. The projection of bodily schemata is also apparent in the way we internally differentiate a vehicle so that we might speak not just of its 'body', but also of its 'headlights', its 'tail' or 'arse-end', its steering arms and so on. Conversely, a vehicularisation of the human body is evident in idioms such as 'punching someone's lights out', 'making tracks' or 'going off the rails'. This dialectic between corporealisation of vehicles and a vehicularisation of the body is no less evident in the tropes used by the Indigenous people of the Kimberley region of north-western Australia where the forms of embodiment that are projected onto (and introjected from) vehicles take on the specificity of local body imagery and the particular ways in which vehicles are used there.

At the conclusion of one long bush trip, my wife, our Ngarinyin neighbour Molly, and myself had almost arrived back in the settlement where we lived when the rear axle of our vehicle disintegrated just as we pulled off the main road onto the long, corrugated track leading home. Molly, an elderly widow, clambered out of her seat, sat herself down on the dirt road and began to cry loudly and inconsolably not just for herself but for the mutika (motorcar): 'that ungulman [old woman], he bin carry we bala every place...finish up now... praply buggered up.'

Other moving examples of this corporealisation of vehicles in another part of Indigenous Australia appear throughout the Warlpiri Media TV series Bush 
Mechanics. ${ }^{1}$ In one of the more reflective interludes sandwiched between comedic scenes, a senior man picks through the rusted bones of a prewar Chevrolet truck. Pointing to the disembodied monolith of the engine block, he wistfully muses on how this particular truck - on which he and his age-mates first learnt their mechanical skills - 'bin grow us up that one', and then goes on to say how its now disintegrating presence in the country continues to act as a 'witness for us'. Gertrude Stotz also recorded some of the personalising statements about vehicles made by Warlpiri women, including a scenario in which she was admonished for pushing her overheated vehicle too hard by a passenger, who said of the car: 'Your mum got headache, you got to drive slowly.'2

For many Ngarinyin people, what the corporealised vehicle also implies (and this is something I also see in the Walpiri examples just given) is that the vehicle acts as an objectified container of relationships while simultaneously becoming bodily relativised (as in 'made a relative of') to its contents. This is hardly surprising when we consider that our bodily schemata are always inter-subjectively constituted from the face-to-face situations that provide a corporeal mirroring in which we not only recognise, but also build up, images of own bodies. This bodily mirror image - although constituted through social engagements - tends to remain a highly differentiated one marked with the particularities by which we carve ourselves out from others. In terms that resist a Durkheimian tendency towards hypostatising the body image as emblematic of 'society' itself, the pioneering psychoanalyst and phenomenologist of bodily experience Paul Schilder described a dual process of differentiation from, and dependency on, the bodily image of others as one in which

a body image is in some way always the sum of the body-images of the community according to the various relations in the community... There is a social image of the body. These processes between individuals may make them in parts identical. But they are still processes between individuals. When an individual has socialized his postural image it still remains his postural image. There does not exist a postural image of the community, or a 'WE'. ${ }^{3}$

Consonant with this insight, most Ngarinyin people ${ }^{4}$ do not employ images of a single social body even though their bodily schemata definitely take account of the important ways in which close kin are felt to be very much present within

\footnotetext{
1 Warlpiri Media Association 2000, Bush Mechanics: The series, [Video], Warlpiri Media Association, Yuendumu, NT.

2 Stotz, Gertrude 1993, 'Kurdungurlu got to drive Toyota': differential colonizing process among the Warlpiri, unpublished PhD thesis, Deakin University, Melbourne, p. 176.

3 Schilder, Paul 1964 [1935], The Image and Appearance of the Human Body: Studies in the constructive energies of the psyche, International Universities Press, New York, p. 302.

4 But see David Mowaljarlai's depiction of Australia as a single body in Mowaljarlai, D. and Malnic, J. 1993, Yorro Yorro: The spirit of the Kimberleys, Magabala Books, Broome, WA.
} 
each person's body. What is most salient here is something akin to what Roy Wagner has dubbed a 'fractal' type of personhood ${ }^{5}$ - that is, one in which any partial image of a person and their social world is always constituted in relation to others at different scales. Ngarinyin body imagery manifests this fractal quality most clearly in the experience of muscle twitchings (dambaj ngama), which correspond with a codified and readily interpretable set of relationship categories, and with particular persons with whom reciprocal rather than identical body images are shared. ${ }^{6}$

These networks of kin, which constitute the relational body for Ngarinyin people, are readily projected onto motor vehicles in a way that recalls Fred Myers' account of the Pintupi experience of country 'as the embodiment of kin networks and as a record of social ties that can be carried forward in time'. ${ }^{7}$ In the northern Kimberley, the travellers' countrymen perceive community vehicles (these days usually a four-wheel-drive, flat-bed truck with a roll-cage on the tray) as exactly that kind of mobile condensation of country and people. The truck's own relationship to country is rendered concretely by the insignia emblazoned on the driver's door, which often conflates a local totemic signifier with some kind of emblem of the settlement's recognition by one of the various government funding agencies. Local Aboriginal people who might be passing along the $700 \mathrm{~km}$-long gravel and dirt Gibb River Road (the only main road in the northern Kimberley region) or sitting down in a roadside settlement quickly identify these vehicles by calling out their well-informed speculations about its place of origin, as soon as its dust cloud or exhaust note is detected: 'Dodnun' or 'Gibb River' or 'Prap Prap might be' or perhaps with the dismissive cry of 'Nothin' - only touris' that one'. ${ }^{8}$

The people travelling on board a community mutika not only endure the manifest discomforts of travelling this way, they also endure (persist) with a certain kind of inter-subjectivity through the shifting panorama of space-time. The concept of a 'moving community' is a very real one in Indigenous northern Australia where whole communities regularly travel together, often leaving just a few elderly people back at their settlement to feed the dogs and 'mind the camp' (a rationalisation commonly used by younger people for taking a holiday from their caring responsibilities for elderly kin).

\footnotetext{
5 Wagner, Roy 1991, 'The fractal person', in M. Strathern (ed.), Big Men and Great Men, Cambridge University Press, Cambridge.

6 Redmond, Anthony 2001, 'Places that move', in A. Rumsey and J. Weiner (eds), Emplaced Myth: The spatial and narrative dimensions of knowledge in Australian Aboriginal and Papua New Guinea societies, University of Hawai'i Press, Honolulu, pp. 120-38.

7 Myers, Fred R. 1986, Pintupi Country, Pintupi Self: Sentiment, place and politics among Western Desert Aborigines, University of California Press, Berkeley, p. 65.

8 See also ibid., p. 63; Young, Diana 2001, 'The life and death of cars: private vehicles on the Pitjantjatjara lands, South Australia', in D. Miller (ed.), Car Cultures, Berg, Oxford, p. 39.
} 


\section{What bodily containers contain}

An experience of containment is a strong component of travelling in a community mutika - first because of the limitations on available vehicle resources, which means that the travellers' bodies tend to be forced tightly together on the tray of the truck, wrapped up in various pieces of bedding or clothing to keep out dust, rain or wind. This sense of containment varies in its intensity according to the prevailing social situation. When travelling for funerals or initiation ceremonies, for instance, the age and gender-based hierarchisation of space pertaining both between the travellers within their truck and between those enclosed within it and the surrounding social world is at its most intense. This modality tends to create an inward-looking, centripetal group of bodies that finds its most intense form in travellers' bodies being entirely obscured beneath blankets and canvas tarps while passing through an area where Law ceremonies are occurring. ${ }^{9}$ In contrast with this, a travelling group which has been drinking alcohol in town and is consuming the remains of their purchases en route to a home settlement (where alcohol may be officially banned) tends to be at their most outwardly demonstrative, entropically scattering emptied containers, personal items, initial high spirits, and the subsequent arguments and cursing across the country as they head for home.

Travelling in a community mutika always involves a tension between mobility and forced immobility, since it is the vehicle itself - as a mechanical, external shell of the body - which is now possessed of vitality and movement while the body of the traveller might gradually succumb to a heaviness and stillness that ideally lead to sleep or reverie, as the traveller's body is transported through the world. ${ }^{10}$ The strictures of community mutika travel tend to induce experiences of the containment of a relatively immobile body within a larger mobile body, which gives rise to a sense of self continuing through time against the shifting panorama of country slipping past the traveller, ideally at least, at a fairly regular pace. The changing road surface, the dips ('deeps' in Ngarinyin Kriol) and steep inclines of the road, negotiated by a good driver who knows how to work through the gears and maximise the engine's torque, are felt as periods of vertical variation occurring against a more or less continuous horizontal movement, allowing one's body to anticipate and merge with the vehicle in order to maximise one's equilibrium. These broader rhythms nevertheless encompass all sorts of jarring shocks such as those caused by badly corrugated stretches of road, which set off a shuddering within the broader rhythms of

9 On a mobile Aboriginal 'endosociality', see Peterson, Nicolas 2004, 'Myth of the "walkabout": movement in the Aboriginal domain', in J. Taylor and M. Bell (eds), Population Mobility and Indigenous Peoples in Australasia and North America, Routledge, London, p. 235; also Young, 'The life and death of cars', p. 44. 10 See also Munn, Nancy 1986, The Fame of Gawa: A symbolic study of value transformation in a Massim (Papua New Guinea) society, Cambridge University Press, Cambridge, UK, and New York, pp. 76-9. 
the road over several kilometres. Judging the correct speed to float over the corrugations without losing control is part of the skill required to drive on such roads. Potholes and bumps - unless previously committed to memory by one of the travellers who shouts out a warning as they approach - usually come out of the blue and often cause the passengers to yell out their disapproval and call for the driver to slow down. These same events might also start children laughing at their fellow travellers' loss of bodily control. Children seem to have an infinite appetite for the slapstick humour of bodies becoming subject to uncontrollable forces, a humour that is contained only by the threats of being thumped or 'growled' at by those trying to recover their poise.

The fact that mutika journeys are often made sitting on one's buttocks with legs crossed or drawn up against the body, or lying down on well-used foam mattresses, usually pressed against the bodies of other travellers, sometimes laying one's head in another's lap or shoulder or having another body leant against one's own, means that an intimate inter-corporeality pervades the group of travellers. This mode of inter-subjective space-time brings into play templates of experiencing the body emerging from other dimensions of self-other relationships in which bodily immobility is similarly the precondition of a selftranscending mobility. While fathers tend to carry children on their shoulders like hunted game, the characteristic way for the mother or sister to carry a young child is on the hip and the point of contact between the two bodies is buttocks to hip, rather than buttocks to shoulders. Elevation, safety and the joy of effortless transport ensue for the child. The enclosed, often uncomfortable cramping of the body within the mobile shell of a community mutika, then, readily induces psychophysical resonances with the maternal holding and lifting up of the child's body - something that seemed to me to be made explicit in Molly's grieving as well as Stotz's truck's 'maternal headache' (see above).

An ideal vehicle trip is one in which the traveller can enter into periods of 'knock-out sleep', waking up close to one's destination, interspersed with seeing and/or interacting in other ways with interesting things or people along the way, including animals such as goanna or bush turkey that might be hunted, or a vehicle full of kin and friends (and maybe recently hunted game) travelling the same route in either direction. Interactions also occur with features of the landscape, which might elicit historical, biographical and/or mythical stories from amongst the travellers. Adults often express a wistful envy at the ability of children to achieve 'knock-out sleep' — with its sense of magical transportationseemingly at will. Travelling in settlement style, which adults often undertake with all their worldly goods stuffed into the ubiquitous plaid plastic carry-all bag, has the potential to produce simultaneous experiences of enclosure and dispersal across the country. The experience of enclosure is inherent to being closely surrounded by kin within the confines of the vehicle. This is intensified 
in the northern Kimberley by the fact that the Gibb River Road frequently flows along valleys between sandstone escarpments that rise up around the road so that the traveller is 'inside the country' in a very psychophysical way. This sense of enclosure is intermittently broken by 'jump-ups' (where the road ascends an escarpment), which give the traveller a wide view out across the country, allowing the traveller's body image to expand to the horizon of the next range, and generating a transcendence of one's bodily capacities, intensifying the transcendence already begun by the corporeal identification with the superhuman capacities of the vehicle itself. The jump-ups on the Gibb River Road are now increasingly bituminised for a few kilometres either side to offset the effects of erosion so the experience of momentarily emerging off the dust and corrugations is synthesised with the smooth flight of the vehicle into sudden panoramic expanses opening up before the traveller.

The view of a distant land feature is immediately an object of the traveller's spatiotemporal intentionality - either something to 'catch up' with or a 'poor bala' being left behind. A bodily leaning into the future or the past can be generated by the forward thrust of the vehicle and a sense of the country rushing past one's body, which continually projects itself onwards and outwards from a present moment in time. ${ }^{11}$ The value placed on 'look 'em round country' implicates vision as a central modality for the extension of the self through the world. ${ }^{12}$ When looking out from high points in the ranges, a person is able to 'expand' - warl - into the country before them, to become 'satisfied or pleased' with themselves. As Husserl notes, human experience of the here and now 'always expands in to extension and therefore is never without its halo... it is continuously mediated with the not now ${ }^{\prime}{ }^{13}$ and, I would add, with the not-here (indeed, a parting remark commonly made by Ngarinyin people when embarking on a journey is 'All right, I'm not here!'). In these kinds of expressions, images of bodily interaction with country evoke Schilder's description of the

continual change of experience concerning the imaginary centre of the ego. There is a continual wandering of experience in centrifugal and centripetal directions... a tendency to keep the body image within its confines and to expand and extend it, to keep its parts together and to dissipate it all over the world. ${ }^{14}$

11 'Everything I see is in principle within my reach, at least within reach of my sight, and is marked upon the map of the "I can".' Merleau-Ponty, M. 1964, The Primacy of Perception, Northwestern University Press, Chicago, p. 162.

12 On Yolngu equations of seeing and travelling, see also Tamisari, Franca 1998, 'Body, vision and movement: in the footprints of the ancestors', Oceania, vol. 68.

13 Husserl, E. 1964, ‘The phenomenology of internal time consciousness', M. Heidegger (ed.), J. S. Churchill (trans.), Indiana University Press, Bloomington, p. xxvii.

14 Schilder, The Image and Appearance of the Human Body, p. 301. 
The descent out of the ranges onto the virtually treeless flood plains and mudflats in the Derby hinterland - which is relatively 'stranger' country for some of those Ngarinyin people living on the Gibb River Road-offers presentiments of an open-endedness that is sporadically marked by the historical trajectories of individuals who have accumulated some kind of 'story' there through their work history or other biographical associations. ${ }^{15}$ This open-endedness is amplified by the desirable but nevertheless dangerous unpredictability of the social scene around town. The compact sociality induced by community mutika travel is intensified once in town, where the travellers who have arrived on a vehicle tend to stick to it as though it were an exoskeleton providing support and security in the often stressful town environment and through which a person can mediate the indeterminacies of the wider world. This feeling-tone is in marked contrast with the experience of being at home, which involves travelling through the well-wooded ranges, being saturated in the relatively more predictable rhythms of small settlement life, and enjoying the relative autonomy afforded by one's home camp.

\section{Travelling: Then and now}

Though older people are enthusiastic about their relatively recent access to motor vehicles, what some of them mean by 'really travelling' is walking-a term also applied to the rhythmic, creative journeys of mythic beings across the country. 'Anybody [come] along from bush. Now these days we don't do that, now we got truck everywhere - we don't travel anywhere.'16

This lament was, paradoxically enough, made by an older man whose unceasing back-and-forth movements by mutika are legendary in the region. It would seem that for him and many of his peers, the pendulum-like motion between town and settlement, and between his own settlement and adjacent settlements, following the fixed groove of the Gibb River Road, has a quality of sameness about it that 'foot-walking la bush' never did. For this man and many of his age cohorts, the welcome unpredictability of town life exerts a strong attraction, alternating with the repulsion that eventually drives them back to their home settlements to restore themselves socially, physically and emotionally. What seems to be often felt to be missing from mutika travel for older people - whose lives have long been strongly anchored in a set repertoire of places and kinis the unpredictable encounter, something now more readily attainable when camping in town. Bakhtin describes this quality as being a central trope in the imagery of being 'on the road', where 'any contrast may pop up, the most

15 See also Rumsey, Alan 1994, 'The Dreaming, human agency and inscriptive practice', Oceania, vol. 65, pp. 116-31.

16 The late Nyalali Reggie Tataya. 
varied fates may collide and interweave with one another' ${ }^{17}$ Even with the large complement of 'touris' now travelling the Gibb River Road in the dry-season months, there is seldom any interaction with such strangers apart from the odd curious word exchanged at the widely dispersed fuelling points. 'Touris', like the 'gabmin man' (government departmental officers), sail past in an airconditioned cocoon or parallel universe, usually only one or two persons to a car, and, with tourists, three or four cars to a convoy.

For many senior Ngarinyin people, travelling is a mode of being in the world that still articulates with the imagery of ancestral beings - wanjina - 'carrying country' on their shoulders from place to place. Identifications made between wanjina and the wet-season cloud formations (an.guban), 'the travellers' are also incarnate in large boulders sitting on the country. ${ }^{18}$ The remarkable symbolic equivalence that is created here between cloud and stone - the first by nature airborne and mobile and the other heavy and sedentary - highlights a serial transformation linking living persons and the alternating capacities for mobility and stopping in one place characteristic of the figures of wanjina and wunggurr - the ubiquitous and watery body of the Rainbow Serpent.

Wanjina conduct their peregrinations through the wet season, appearing as the cumulonimbus thunderheads accompanying the north-west monsoons (December to April), after which they are said to 'lay 'emself down' in the form of the deep freshwater pools to which the running rivers contract as the dry season (May through to November) ensues. Ngarinyin speakers use the term 'we awani' for this 'laying down' of the wanjina as they pressed themselves into the soft, jelly-like surface of the Earth in the originary epoch (Larlan). Gulingi, rain clouds, make the bodies of wanjina visible as distinct and mobile entities on the horizon as the monsoon season begins.

In the dry season, the cloud mass breaks up again into individual clusters before disappearing and the wanjina return to their resting places in their own countries. The long moving ribbons of river courses slowly break up into a series of isolated rock pools - the ngawan or 'living water' that never disappears no matter how dry the season. Despite this dry-season scattering of the body of wunggurr into distinct, emplaced fractals of itself (embodied in the permanent rock pools), the body of wunggurr becomes submerged in the Earth and beneath the water, leaving only the upper parts showing as 'islands' of stone.

17 Bakhtin, Mikhail M. 1981, The Dialogic Imagination, University of Texas, Austin, p. 243.

18 Redmond, 'Places that move'; Crawford, I. M. 1968, The Art of the Wandjina, Oxford University Press, London; Lommel, A. 1996 [1952], The Unambal: a tribe in northwest Australia, unpublished English translation, F. Zanvoort, Missabotti, NSW; Mowaljarlai and Malnic, Yorro Yorro; Mowaljarlai, D. and Vinnicombe, P. 1996, 'That rock is a cloud: concepts associated with rock images in the Kimberley region of Australia', in Helskog, K. and Olsen, B. (eds), Perceiving Rock Art: Social and political perspectives, Novus Forlag, Oslo. 
The wanjina's alternation between moving and lying down, the appearance and disappearance of the rain clouds each wet season, and the flowing rivers gradually contracting to isolated pools, are all processual moments in the continual reanimation of country. One of the many stories dealing with ancestral travelling and stopping speaks of the emission of fluid bodily substancesmucus - by an ancestral Kangaroo, Walamba, and the drowning of his wives in what becomes a permanent spring. This event is quickly followed by Walamba's metamorphosis into an iconic pillar of enduring materials and significance: a large cypress pine (a Ngarinyin version of Lot's Pillar perhaps).

A useful contrast can be drawn between these ecological/cosmological flows and the high degree of mobility of contemporary Kimberley Aboriginal people who (during the dry season) travel back and forth between station settlements and towns such as Derby and Wyndham but become relatively constricted in towns or settlements during the wet season. The (now receding) impact of the pastoral work regime has meant that the cycle of travelling for adolescent male initiation ('Law'), formerly undertaken in the middle of the dry season, now occurs about Christmas, just before the river crossings start to flood. Though the pastoral labour regime, in combination with the transition to dependence on vehicular travel on uncertain seasonal roads, long ago took over setting the agenda for Kimberley people's movement, dry-season travelling continues to be undertaken for secular purposes such as visiting relatives, mustering and droving cattle, and attending sports carnivals, rodeos and music festivals. In some respects, then, the movements of people - which once closely mirrored those of wanjina and the water that comes with them-have become their dialectical opposite. Now people move in the dry season when water is still, while in the wet season water moves while people are still.

During the wet season, visitors tend to overflow from the houses of those relatives who maintain permanent camps in the reserves around town, often aggravating interfamilial conflicts as the limited resource base available in these reserves comes under even more intense pressure. At the same time, relationships between kinfolk might be re-energised by imposing an intensified sociality commonly marked by long, hot evenings of card playing, conversation, drinking parties, fights, band performances, children's parties, basketball games and church-organised events. This tends to create a highly charged social atmosphere (drinking alcohol is known as 'charging up') and large groups of young men from the same settlement are usually to be seen milling about in the main streets of town, sticking close together while remaining alert to the possibilities for action offered up by being abroad in public spaces. There is also a great deal of motoring back and forth between the town camps and the edge of the river flood plains to fish and hunt goanna since the hot season is also goanna and barramundi season. In this sense, there is actually a great deal of mobility 
but most of it occurs within the very narrow confines of the reserves, the town area and between individual households. From these narrow bases there is a constant movement back and forth into the main streets of town. Rather than large-scale travelling, then, people tend to engage intensively with each other and to move at high frequency within the limited space available to them during the big wets.

Alongside the values placed on mobility within contemporary Kimberley settlements there is also a pervasive moral discourse about why people should 'stop in one place' at various phases in their lives. Widows (baran) in particular, once they have made the initial move from their deceased spouse's camp, are expected to remain in or near their new camps and to look after their own needs until the long period of mourning is over. Recently widowed women often make a public show of virtue out of this constraint by making themselves focal reference points for moral order within the highly mobile contemporary communities through embodying social boundedness and stasis.

At the opposite pole from the stasis of widowhood, children are some of the most mobile members of these communities and might be bundled aboard vehicles to visit relatives at other settlements for weeks or months at a time. These children are often transported back and forth between the camp of their mother (who might be struggling to cope with younger infants) and that of the child's mother's mothers, where they are often received with delight qualified by oblique or direct criticism of the mother's quality of care. This shifting back and forth of children between a parent and grandparent also serves the evasion of pressure from welfare and school authorities to keep the child in one place so they can attend school regularly. Only male teenagers move about with anything like the frequency of these younger children. The high mobility of adolescent males in this social world might be seen as congruent with one of the characteristics of 'bride-service' societies, as described by Collier and Rosaldo, in which 'the exchange of women is usually accompanied by moving men around'. ${ }^{19}$

Local understandings about embodiment are centrally concerned with the transformation of experiences of bodily heaviness and stasis into weightlessness, mobility and the throwing off of enclosing surfaces-experiences that encompass and mutually generate each other. To take one common example, it is only when a vehicle comes to an unexpected halt that the pleasure of being transported without personal exertion (a psychophysical state for which someone once coined the term 'velocitude') is transformed into distress and

19 Collier, J. and Rosaldo, M. 1981, 'Politics and gender in simple societies', in S. Ortner and H. Whitehead (eds), Sexual Meanings: The cultural construction of gender and sexuality, Cambridge University Press, Cambridge, pp. 275-329, at p. 300. 
longing for a return to the experience of the spatio-temporal flow of the road. There is always palpable relief when a broken-down vehicle gets moving again and all the discomfort of being cramped and uncomfortable on the tray-back of the vehicle is forgotten as the traveller's body is once again identified with the 'flying' vehicle. The pleasure of extending oneself into the world is, for a while at least, paradise regained - a condition made visible in the ebullient conviviality that tends to possess passengers who might have already begun to anticipate an uncomfortable, and maybe hungry, night stuck on the road.

The tension between this desire for movement and the state of rest that gives movement meaning is aptly captured in the Ngarinyin word ' $g i$ ' - a term used to describe one's grasping of a patri-totemic identity, something paradigmatically stable and emplaced, but that was also glossed by one man as to "push-start motorcar with flat battery' because gi means 'to push out', 'to move' something that is resistant. ${ }^{20}$ Bakhtin has argued that this tension between the flow of time and the sedentary tendencies of place is most fully articulated in 'the chronotope of the road', in which '[t]ime, as it were, fuses together with space and flows in it (forming the road)... its fundamental pivot is the flow of time' ${ }^{21}$

The transcendence of the capacities of the self through the identification produced between the body of the traveller and their vehicle is enhanced by an ability to use one's knowledge of the interior workings of the machinethat is, having enough knowledge to get it going again when it breaks down, a knowledge that tends to be unevenly distributed and thus enhances the prestige of those who can manage such knowledge effectively. ${ }^{22}$ The human capacity to organise enteroceptions/images arising from the internal workings of the body in a productive way allows the coordination and the creation of desirable effects on the world and provides the corporeal basis of mechanical intuition. ${ }^{23}$ Bush Mechanics was a particularly brilliant treatment of the improvisatory and intuitive genius required to keep vehicles alive and running in the Tanami Desert. The fantasies that those stories allowed themselves to entertain speak clearly to the animistic thinking through which we all interact with motor vehicles. This capacity was epitomised by the magical Jupurrula character who is depicted as being in direct contact with ancestral forces and who is also a hilarious realisation of the dreams of omnipotence that are continually stimulated

\footnotetext{
20 See also H. H. C. Coate and A. P. Elkin 1974, Ngarinjin-English Dictionary, 2 vols, Oceania Linguistic Monograph No. 16, University of Sydney, NSW, p. 241; also Stotz, 'Kurdungurlu got to drive Toyota', p. 226, on 'battery', the 'fire producer' of an engine, as a taboo word in Warlpiri.

21 Bakhtin, The Dialogic Imagination, p. 244.

22 Appadurai, Arjun 1986, 'Introduction: commodities and the politics of value', in A. Appadurai (ed.), The Social Life of Things: Commodities in cultural perspective, Cambridge University Press, Cambridge, UK, and New York, p. 41.

23 Appadurai (ibid., p. 41) has made the point that the social knowledge required both to produce and to consume things has 'technical, mythological and evaluative components' rather than the technical and evaluative/mythological aspects being respectively allocated between producer and consumer.
} 
and subverted by these complex objects. It is worth remembering here that the mechanistic European view of the world is historically recent (circa seventeenth century), prior to which the world was conceived as 'something animate, alive and flourishing yet susceptible to decay and death, mirroring the life-cycle of individuals'. ${ }^{24}$ A mechanical view of the world is in fact a particular kind of extension, rather than a refutation, of our dreams of bodily transcendence as well as of the concomitant potential for failure of those dreams, which leads us, for example, to talk about a motorcar 'dying' ${ }^{25}$

Old age, bodily exhaustion and widowhood are all factors that mark the body's transformation from high mobility to stasis. Like wanjina, the travelling beings who eventually became 'tired' and 'stopped in one place', elderly people gradually have their range of mobility circumscribed by poor health, lack of control of their own vehicles (and a concomitant lack of offers from younger kin to take elderly people with them) and their own lack of desire to go beyond a domestic arena that they might have made manageable for themselves. Nevertheless, I have been struck by the incredible powers of endurance and spirit of adventure of many older Ngarinyin people and my impression is that Aboriginal 'grey nomads' continue to travel even more frequently and more intensively than their Euro-Australian peers, despite the privations of travelling on a tray-back truck as opposed to an air-conditioned mobile home. For those who stay at home, travelling remains a focus of nostalgia, dreams, songs and the vicarious pleasure of keeping abreast of the movements of those around them. ${ }^{26}$ Like the depleted bodies of the wanjina, which run out of breath, become tired from walking and 'lay 'emself down', very old people often disappear inside their homes for the greater part of the day and night, becoming increasingly inaccessible beyond the canine barrier they often erect around themselves. ${ }^{27}$ At Christian funeral services, hymns of travelling such as the favourite Road of No Return will be sung to accompany the spirit of the deceased person on its journey to Dulugun, the island of the dead - a trip that one senior man, Gowanulli, always described with his characteristic black humour as 'one-way trip that one, that one'.

\footnotetext{
24 Williams, R. 1980, 'Reproduction: a replacement for reciprocity', American Ethnologist, vol. 7, no. 1, pp. 71-85, citing Hallowell (1955:86-87).

25 See Young, 'The life and death of cars', pp. 50-1.

26 This aspect of ageing in Indigenous settlements has been explored by Dianne Austin-Broos, who remarks that '[a]ge is one circumstance among others that can place an individual at the margins of kin relations and, therefore, at the margins of society'. Austin Broos, Dianne 2003, 'Places, practices, and things: the articulation of Arrernte kinship with welfare and work', American Ethnologist, vol. 30, no. 1, p. 120.

27 This wall of dogs that old people often build around themselves serves the multiple purposes of companionship, a personal alarm system, and, in some cases, allows communion with dead relatives who are re-embodied in these dogs. Canine companionship is one of the things that seems to be most sorely missed by the old and frail who are increasingly confined within the walls of the largely European-controlled space of the town nursing home.
} 


\section{Conclusion}

In this article, I set out to show some of the ways in which Kimberley Aborigines deploy a more general human capacity for projecting images of the body onto tools (and of tools onto the body) - in this case, mutikas, which permit an expansion and transcendence of bodily capacities while also noting the potential of vehicles to confine and restrict these capacities (as Nyalali's lament seemed to suggest). I have taken one point of departure from Nancy Munn's ${ }^{28}$ superb analysis of the psychosocial use of canoes in Gawa (Papua New Guinea) and another from Paul Schilder's ${ }^{29}$ still unsurpassed phenomenological study of the body's imaginative representations of itself and others. I also pointed to the ways in which corporeal expansion - and the correlative contractions associated with death, funerals and broken-down vehicles - is achieved in the Kimberley life world. The much less articulated bodily experiences inherent to travelling in community mutikas are broadly consonant with the kinds of well-articulated bodily identifications the older generation makes with country. Fundamental to these experiences are the bodily confluences, differentiations and positionings within the vehicle itself, which the traveller must constantly negotiate with fellow travellers and the wider world. 